\title{
The association between maternal nutritional status and physical development of offspring aged 2 years
}

\author{
Lai Jianqiang $^{1}$, Zhao Wenhua ${ }^{2}$, Chen Chunming ${ }^{2}$ and Kong Lingzhi ${ }^{3}$ \\ ${ }^{1}$ Institute of Nutrition and Food Safety-Chinese Center for Disease Control and Prevention, ${ }^{2}$ Chinese Center for Disease \\ Control and Prevention and ${ }^{3}$ Bureau for Disease Control and Prevention, Ministry of Health, Beijing, China
}

Maternal nutrition plays a key role in offspring growth and development. The height and $\mathrm{Hb}$ concentration of infants and young children are influenced by the mother. Much attention has been paid to the impact of maternal nutrition on the health outcomes of children ${ }^{(1,2)}$. The present study aimed to (1) investigate the relationship between the Hb level of children aged 2 years and maternal anaemia and (2) research the effect of maternal nutritional status on child growth in China.

The data presented were collected in the 2002 China National Nutrition and Health Survey. The method of multi-steps cluster sampling was adopted. In order to ensure the inclusion of a sufficient number of babies and young children and pregnant women and women post partum in this survey, additional subjects were included in the sample. Data for weight and height or length of mothers ( $n$ 1380) and children ( $n$ 1380) were analysed according to whether the mother's height was above or below the mean height for women aged 18-44 years of $1.56 \mathrm{~m}$.

The purpose of the analysis for the present paper was to assess the distribution of $\mathrm{Hb}$ among infants aged 0-24 months and assess its relationship with different intermediate, underlying and basic factors, including the following: (1) for children; birth weight, birth order, age, gender, Hb, low birth weight, stunting; (2) for mother; Hb, BMI, age; (3) indicators of socio-economic status, maternal education. Children's data were included in the analyses when they were 0-24 months old and had a complete set of data.

The prevalence of anaemia in children from urban areas was lower than that of children from rural areas $(P<0.05)$. However, there was no significant difference in anaemia prevalence between mothers from urban and rural areas $(P>0.05)$. While the mean $\mathrm{Hb}$ level $(\mathrm{mg} / \mathrm{l})$ for children was 121 (SD 15.9) and 120 (SD 16.1) for urban and rural areas respectively, the corresponding values for the mothers were 131 (SD 14.9) and 131 (SD 15.8).

The prevalence of stunting in children at age 2 years born to mothers with a height $<1.56 \mathrm{~m}$ was $21.0 \%\left(\chi^{2} 23.4, P<0.001\right.$; OR 2.07 (95\% CI 1.83, 2.35)), while that for children born to mothers with a height $>1.56 \mathrm{~m}$ was $11.3 \%$. Thus, the risk for stunting in children at 2 years decreased with increasing maternal height. The prevalence of stunting in children at age 2 years born to mothers with a height between $1.55 \mathrm{~m}$ and $1.60 \mathrm{~m}$ was $10 \%$. The prevalence of stunting for children born to mothers with a height $<1.55 \mathrm{~m}$ and that for children born to mothers with a height $>1.55 \mathrm{~m}$ was 62.7 and $37.3 \%$ of all children in that age-group respectively $\left(\chi^{2} 37.7, P<0.0001 ;\right.$ OR 2.12 $(95 \%$ CI 1.65, 2.71)).

The mean length of children born to mothers with a height $>1.56 \mathrm{~m}$ was $0.024 \mathrm{~m}$ more than that of children born to mothers with a height $<1.56 \mathrm{~m}$. The prevalence of stunting in children at 2 years of age born to mothers with a height $<1.56 \mathrm{~m}$ was 2.07 -fold that of children born to mothers with a height $>1.56 \mathrm{~m}$. Thus, the risk for stunting in children at 2 years of age is lower in children born to taller mothers.

Maternal nutritional status may have an important influence on children's physical development.

1. De Pee S, Bloem MW, Sari M et al. (2002) J Nutr 132, 2215-2221.

2. Phaneendra Rao RS, Prakash KP \& Sreekumaran Nair N (2001) Bahrain Med Bull 23, 22-26. 